\title{
Sigurnost bolesnika u zdravstvenim ustanovama iz perspektive medicinskih sestara
}

\section{Patient safety in healthcare organizations from the perspective of nurses}

\author{
Marijana Neuberg' , Valentina Vincek', Matija Kovačíć, Ivana Herak' , Tina Cikačc \\ 1 Sveučilište Sjever, Odjel za sestrinstvo, Ulica 104. brigade 3, 42000 Varaždin, Republika Hrvatska \\ ${ }^{2}$ Sveučilište Sjever, Odjel za logistiku i održivu mobilnost, Ulica 104. brigade 3, 42000 Varaždin, Republika Hrvatska
}

\section{Sažetak}

Uvod: Sigurnost bolesnika u fokusu je interesa svih zdravstvenih organizacija jer može determinirati kvalitetu života bolesnika nakon završetka njegove hospitalizacije. Međutim, sigurnost bolesnika određena je brojnim faktorima, a jedan od njih su i medicinske sestre koje rade u bolničkim organizacijama. Preopterećenost medicinskih sestara brojnim zadacima, ali i nepravilna komunikacija mogu rezultirati ugrozom sigurnosti. Sigurnost bolesnika predmet je regulacije i zakonodavca koji putem indikatora kvalitete definira potrebu praćenja i poboljšanja postojeće razine sigurnosti bolesnika.

Cilj: Cilj je ovog rada istražiti percepciju medicinskih sestara o sigurnosti pacijenata.

Metode: U istraživanju je korišten Upitnik o kulturi bolesnikove sigurnosti u bolnici (HSOPSC), a u istraživanje je uključeno 209 ispitanika. Kao tehnika prikupljanja podataka korištena je anketa provedena putem Google Forms obrasca tijekom travnja i svibnja 2020. godine. Prikupljene ankete analizirane su pomoću deskriptivne statistike za što je korišten MS Excel program. U svrhu testiranja hipoteza koristio se hi-kvadrat test.

Rezultati: Rezultati istraživanja pokazuju kako medicinske sestre percipiraju sigurnost pacijenata te da postoji razlika u percepciji sigurnosti s obzirom na hijerarhiju zaposlenika u zdravstvenoj ustanovi. Percepcija sigurnosti bolesnika u zdravstvenoj ustanovi mijenja se ovisno o razini obrazovanja te godinama radnog iskustva sudionika.

Zaključak: Budući da smanjena razina sigurnosti može rezultirati pojavom neželjenih događaja, odnosno može smanjiti kvalitetu skrbi za pacijenata, percepcija medicinskih sestara o sigurnosti pacijenata u zdravstvenoj ustanovi, razina njihove edukacije te način izvođenja aktivnosti mogu doprinijeti sigurnosti bolesnika.

Ključne riječi: sigurnost bolesnika, medicinske sestre, indikatori kvalitete

Kratki naslov: Sigurnost bolesnika

\begin{abstract}
Introduction: Patient safety is the focus of all hospitals and can determine the quality of life of a patient. However, patient safety correlates with several factors, and one of them is nurses who work in hospital organizations. Overburdening nurses with numerous tasks and improper communication between them can result in a threat to patient safety. Patient safety is also the subject of regulation that defines the need to monitor and improve the current level of patient safety through quality indicators.
\end{abstract}

Aim: This paper aims to investigate the perception of healthcare professionals regarding patient safety with special reference to nurses and technicians.

Methods: The Hospital Patient Safety Culture Questionnaire (HSOPSC) was used and the survey included 209 respondents. Data were collected via the Google Forms form during April and May 2020. The collected surveys were analyzed using descriptive statistics for the MS Excel program. For testing hypotheses, the hi-square test was used.

Results: Research has shown that nurses organize well when it comes to performing a large number of activities in a short time, as well as when it comes to taking preventive measures aimed at increasing patient safety, which has a positive impact on patient safety.

Conclusion: Reduced level of safety can diminish the quality of patient care, so nurses' perception of patient safety in a health care institution, their level of education, and the way activities are performed can contribute to patient safety.

Keywords: patient safety, nurses, quality indicators

Running head: Patient safety

Autor za korespondenciju/Corresponding author: Marijana Neuberg, Sveučilište Sjever, Odjel za sestrinstvo, Ulica 104. brigade 3, 42 000 Varaždin, Republika Hrvatska, e-mail: marijana.neuberg@unin.hr

\section{Uvod}

Sigurnost bolesnika predstavlja prevenciju, otklanjanje i unapređenje zaštite od neželjenih događaja tijekom procesa zdravstvene skrbi [1], a posebno je važna s obzirom na temeljno načelo u zdravstvenom sustavu koje se odnosi na smanjenje rizika od nanošenja štete bolesniku. Intenzivira- nje promišljanja o sigurnosti bolesnika započinje početkom 90-ih godina prošlog stoljeća porastom broja komplikacija tijekom liječenja i smrtnih ishoda. Unatoč porastu svijesti o važnosti sigurnosti pacijenta, problematika sigurnosti i dalje je u fokusu interesa jer statistički pokazatelji govore da 
od $8 \%$ do $12 \%$ bolesnika koji su hospitalizirani trpi neki vid štete [2]. Nadalje, svake godine unutar bolničkog sustava zemalja Europske nije (EU) od $10 \%$ do $12 \%$ bolesnika pri hospitalizaciji izloženo je nekom od rizika povezanih s ugrožavanjem njihove sigurnosti, odnosno izloženo je štetnom događaju. Od ukupnog broja zaprimljenih bolesnika, na razini EU-a ukupno 37000 bolesnika dobije infekciju koja završi smrtnim ishodom [3]. S obzirom na to, raste važnost promicanja kulture sigurnosti, ali i poduzimanja aktivnosti usmjerenih prema prevenciji rizika koji bi mogli ugroziti sigurnost bolesnika. Budući da su medicinske sestre u svakodnevnom kontaktu s bolesnicima, razvoj svijesti o važnosti sigurnosti bolesnika kod njih može utjecati na povećanje iste [4]. Nadalje, kako bi se povećala sigurnost bolesnika, dolazi i do razvoja modela koji predstavljaju poveznicu između zakonodavca koji donosi pravila vezana za sigurnost i praktičara koji su zaduženi za stvaranje sigurne okoline, odnosno sigurnost bolesnika. Jedan je od takvih modela MaPSaF (Manchester Patient Safety Framework) koji se, između ostaloga, temelji na analizi grešaka i povećanju komunikacije između voditelja te medicinskih sestara i tehničara jer može postojati različit stav o sigurnosti kod spomenutih [5]. Isto tako, kako bi se identificirala postojeća razina sigurnosti bolesnika neophodno je analizirati broj i vrstu neželjenih događaja kao što su to padovi bolesnika i slično, ali i analizirati stavove medicinskih sestara te ostalog osoblja u bolničkoj organizaciji o sigurnosti bolesnika. Istraživanjem i analizom trenutne situacije i stavova vezanih za sigurnost bolesnika mogu se identificirati područja poboljšanja koja mogu biti vezana ne samo za kulturu sigurnosti unutar bolničke organizacije već i zahtjeve zakonodavca [6].

S druge strane, smanjena razina sigurnosti bolesnika, odnosno posljedice smanjene razine sigurnosti bolesnika mogu utjecati na duljinu hospitalizacije i na troškove liječenja u slučajevima kad bolesnik pretrpi neželjeni događaj kao što je fraktura, hematom i slično. $U$ istraživanju autora Carey i Stefos [7] identificirano je da troškovi takvih ozljeda mogu biti značajni te mogu utjecati na financijsko poslovanje bolničke organizacije. Drugim riječima, ako se sigurnost bolesnika sagledava kroz upravljački aspekt, nedovoljna razina sigurnosti može rezultirati pojavom novih troškova i rizikom vezanim za pokretanje pravnog postupka protiv organizacije. Dolazi do propitkivanja aktivnosti koje medicinsko osoblje provodi tijekom svojeg rada. Posljedično, opisano može rezultirati i padom reputacije bolničke organizacije kao sigurne za bolesnika.

Dakle, sigurnost hospitaliziranih bolesnika imperativ je i stoga je neophodno definirati mjere koje će biti usmjerene prema povećanju sigurnosti i smanjenju potencijalnih neželjenih događaja. Republika Hrvatska (RH) putem politike javnog zdravlja i prema načelima zdravstvene zaštite definirala je sigurnost pacijenata kao jedan od indikatora kvalitete pružene zdravstvene usluge [8]. Indikatori sigurnosti bolesnika odnose se na alate koji se upotrebljavaju prilikom definiranja mjera i postupaka usmjerenih prema prevenciji mogućih neželjenih događaja koji bi ugrozili sigurnost pacijenta [9]. Definiranje i praćenje indikatora sigurnosti bolesnika te indikatora kvalitete pružene zdravstvene njege osnova su za identifikaciju mogućih pobolj- šanja u procesu zdravstvene skrbi. Kvalitetno upravljanje zdravstvenom organizacijom uključuje kontinuirano unaprjeđenje zdravstvene skrbi te njezinu stalnu usmjerenost prema potrebama korisnika.

Sustavi upravljanja kvalitetom neposredno mogu doprinijeti i povećanju sigurnosti bolesnika, primjerice, korištenje norme ISO EN 15224:2017 koja definira potrebu usvajanja pristupa utemeljenog na evaluaciji rizika. Rizici koje organizacija mora evaluirati također mogu utjecati na sigurnost bolesnika [10].

Nadalje, sigurnost bolesnika definirana je u Zakonu o kvaliteti zdravstvene zaštite (NN 118/2018) u kojem je navedeno da bolničke organizacije moraju odrediti mjere koje će biti usmjerene prema prevenciji i osiguranju pravilnog izvođenja medicinskih postupka za sve pacijente. Također se navodi izvještavanje o provedenim mjerama usmjerenima prema povećanju sigurnosti [11, 12].

Medicinske sestre najbrojniji su zdravstveni djelatnici koji sudjeluju u prevenciji neželjenih događaja, njihovom ranom prepoznavanju te zbrinjavanju pacijenta po neželjenom događaju.

Jasna komunikacija, razvijena svijest i stalna edukacija medicinskih sestara i tehničara, ali i ostalog osoblja u bolničkoj organizaciji, može pozitivno utjecati na sigurnost bolesnika [13].

\section{Metode i sudionici}

\section{Metode}

Kao tehnika prikupljanja podataka korištena je anketa provedena putem Google Forms obrasca tijekom travnja i svibnja 2020. godine u sklopu izrade diplomskog rada autorice Vincek (2020) [14]. Anketa je distribuirana na društvenoj mreži Facebook članovima grupe diplomskog studija sestrinstva, potom članovima grupe Hrvatsko društvo medicinskih sestara / tehničara digestivne kirurgije, Medicinske sestre / tehničari zajedno te Podrška medicinskim sestrama i tehničarima. U istraživanju je korišten Upitnik o kulturi bolesnikove sigurnosti u bolnici (HSOPSC) razvijen u okviru Agencije za istraživanje i kvalitetu zdravstvene skrbi (Agency for Healthcare Research and Quality - AHRQ). Sastoji se od sedam odjeljaka, odnosno odjeljka o trenutnom mjestu rada ispitanika, odjeljka o rukovoditelju ispitanika, odjeljka o komunikacijama unutar odjela na kojem je ispitanik zaposlen, odjeljka o prijavi učestalosti neželjenih događaja, odjeljka o ocjeni sigurnosti bolesnika, odjeljka o bolničkoj organizaciji u kojoj radi ispitanik te odjeljka o demografskim podacima ispitanika. $U$ anketnom upitniku korištena je Likertova skala s pet ponuđenih stupnjeva: izričito se ne slažem (uz vrijednost odgovora 1), ne slažem se (uz vrijednost odgovora 2), ni jedno (uz vrijednost odgovora 3), slažem se (uz vrijednost odgovora 4) i izričito se slažem (uz vrijednost odgovora 5). Veća srednja vrijednost odgovora ukazuje na potvrdu izjave dane u anketi, a koje su prikazane u tablici 2, dok manja srednja vrijednost ukazuje na manje slaganje s danom izjavom u tablici 2. Prikupljeni podaci analizirani su pomoću deskriptivne statistike za što je korišten MS Excel program. U svrhu testiranja hipoteza koristio 
se hi-kvadrat test. Značajnost razlika komentirana je na razini vjerojatnosti $p<0,05$.

\section{Sudionici}

U istraživanju je sudjelovalo 209 sudionika. Od ukupnog broja anketiranih sudionika, 189 sudionika istraživanja pripadnice su ženskog spola $(90,4 \%)$. Ukupan broj muških ispitanika iznosi 20 (9,6\%). Sudionici su zaposleni i rade na radnom mjestu medicinska sestra / medicinski tehničar. Sukladno primarnom mjestu rada, 66 sudionika (31,5\%) radi u području kirurške djelatnosti, 39 (18,7\%) ispitanika radi u području internističkog odjela, 56 (26,8 \%), ispitanika radi u području gastroenterologije, hemodijalize i traumatologije, dok 39 (23,0 \%) radi na ostalim odjelima (palijativa, pedijatrija, psihijatrija, neurologija i objedinjeni hitni bolnički prijem).

U tablici 1 prikazan je broj sudionika koji su obuhvaćeni istraživanjem s obzirom na radno iskustvo.

Što se tiče obrazovanja, 53,6 \% ispitanika prvostupnici/prvostupnice su sestrinstva, 30,1\% ispitanika čine medicinske sestre / medicinski tehničari srednje stručne spreme, dok $16,3 \%$ ispitanika ima titulu magistar/magistra sestrinstva.

\section{Hipoteze}

U istraživanju su postavljene sljedeće hipoteze:

H1: Godine radnog staža medicinskih sestara / tehničara ne utječu na ocjenu sigurnosti bolesnika;

H2: Razina obrazovanja medicinskih sestara / tehničara ne utječe na ocjenu sigurnosti bolesnika.
TABlica [1] Sudionici s obzirom na radno iskustvo

\begin{tabular}{lcc}
\hline Staž (godina) & Broj sudionika & Postotni udio (\%) \\
\hline $1-5$ & 56 & 26,8 \\
\hline $6-10$ & 29 & 13,9 \\
\hline $11-20$ & 50 & 23,9 \\
\hline $21-30$ & 53 & 25,4 \\
\hline$>31$ & 21 & 10,0 \\
\hline Ukupno & 209 & 100 \\
\hline
\end{tabular}

\section{Rezultati istraživanja}

U tablici 2 prikazani su rezultati istraživanja. Rezultati istraživanja pokazuju da medicinske sestre imaju razvijenu svijest o važnosti sigurnosti pacijenata s obzirom na to da su sudionici potvrdili kako poduzimaju mjere koje su usmjerene prema povećanju sigurnosti pacijenata. Osim toga, istraživanje je pokazalo kako sudionici međusobno surađuju prilikom obavljanja aktivnosti što je posebno važno zbog opsega posla, odnosno broja radnih sati sudionika.

Jedan od problema s kojim se sudionici susreću u provedenom istraživanju je razmjena informacija između odjela te problem postavljanja pitanja vezanih za događaj koji nije planiran. Nadalje, istraživanje je pokazalo kako sudionici percipiraju da rukovoditelj odjela često zanemaruje sigurnost bolesnika smještenog na odjelu te stvara pritisak zaposlenicima da odrade posao za koji nije definirana cijena rada. Navedeno na zaposlenike može djelovati demotivirajuće.

TABLICA [2] Rezultati istraživanja i opisna statistika

\begin{tabular}{|c|c|c|}
\hline Opisna statistika & $\bar{x}$ & $\mathrm{~S}$ \\
\hline Kada treba puno posla obaviti u kratkom vremenu, zajedno radimo kao tim da bi se posao dovršio. & 3,81 & 1,051 \\
\hline Mi aktivno poduzimamo mjere za poboljšanje sigurnosti bolesnika. & 3,81 & 0,93 \\
\hline Osoblje slobodno upozorava ako uoči nešto što može imati negativan učinak na liječenje bolesnika. & 3,70 & 1,079 \\
\hline Naši postupci i organizacija rada dobro preveniraju pogreške. & 3,59 & 0,972 \\
\hline Nikada ne žrtvujemo sigurnost bolesnika da bismo napravili više posla. & 3,53 & 1,079 \\
\hline Informirani smo o pogreškama koje se dogode na odjelu. & 3,50 & 1,161 \\
\hline Na ovom odjelu raspravljamo o načinima kako spriječiti ponavljanje pogrešaka. & 3,45 & 1,18 \\
\hline Osoblje na ovom odjelu radi dulje no što je poželjno s gledišta sigurnosti bolesnika & 3,44 & 1,069 \\
\hline Na tom odjelu zaposlenici podupiru jedni druge. & 3,44 & 1,023 \\
\hline Moj supervizor/rukovoditelj uzima u obzir prijedloge osoblja za poboljšanje sigurnosti bolesnika. & 3,39 & 1,189 \\
\hline Na ovom odjelu ljudi poštuju jedni druge. & 3,33 & 1,048 \\
\hline Radimo po „kriznom modelu” nastojeći učiniti što više, što brže. & 3,31 & 1,039 \\
\hline $\begin{array}{l}\text { Moj supervizor/rukovoditelj izražava pohvalu kada je posao obavljen prema usvojenim principima sigurnosti } \\
\text { bolesnika }\end{array}$ & 3,25 & 1,292 \\
\hline Kada dio odjela bude zatrpan poslom, ostali priskoče u pomoć. & 3,23 & 1,199 \\
\hline Nakon što uvedemo promjene da bismo poboljšali sigurnost bolesnika, vršimo procjenu učinkovitosti. & 3,21 & 0,92 \\
\hline Bolnički odjeli ne surađuju najbolje međusobno. & 3,21 & 1,019 \\
\hline Bolnički odjeli dobro zajedno surađuju da bi bolesnicima pružili najbolju skrb. & 3,21 & 1,097 \\
\hline
\end{tabular}




\begin{tabular}{|c|c|c|}
\hline Čini se da se bolnički menadžment interesira za sigurnost bolesnika samo nakon što se neželjeni događaj dogodio. & 3,20 & 1,151 \\
\hline Kada se dogodi pogreška koja može naškoditi bolesniku, ali nije naškodila, koliko često to prijavite? & 3,19 & 1,304 \\
\hline Bolnički menadžment stvara klimu koja promovira sigurnost bolesnika. & 3,15 & 1,062 \\
\hline Osoblje se boji da će pogreške koje su im se dogodile ostati zabilježene u njihovom dosjeu. & 3,11 & 1,132 \\
\hline Osoblje osjeća da se njihove greške usmjeravaju protiv njih. & 3,05 & 1,136 \\
\hline Kada se prijavi neželjeni događaj, osjeća se kao da je ukazano na osobu, a ne na problem. & 3,04 & 1,176 \\
\hline Prava je slučajnost da se ovdje ne događaju puno ozbiljnije pogreške. & 2,96 & 1,263 \\
\hline Kada se dogodi pogreška, ali bude uočena i ispravljena prije nego što našteti bolesniku, koliko često to prijavite? & 2,94 & 1,352 \\
\hline Ovdje pogreške dovode do pozitivnih promjena. & 2,89 & 1,059 \\
\hline Dobra je suradnja među bolničkim odjelima koji trebaju raditi zajedno. & 2,89 & 1,02 \\
\hline Kada se dogodi pogreška, ali nema potencijal štetnih posljedica za bolesnika, koliko često to prijavite? & 2,83 & 1,33 \\
\hline Dosta se toga izgubi prilikom premještanja bolesnika s jednog odjela na drugi. & 2,81 & 1,079 \\
\hline Osoblje se osjeća slobodnim preispitivati odluke ili postupke pretpostavljenih. & 2,77 & 1,15 \\
\hline Problemi uvijek nastanu pri razmjeni informacija između bolničkih odjela. & 2,75 & 0,978 \\
\hline Dobivamo povratnu informaciju o promjenama uvedenima na osnovi prijava neželjenih događaja. & 2,74 & 1,181 \\
\hline Važni podaci o liječenju bolesnika često se izgube prilikom primopredaje službe. & 2,71 & 1,077 \\
\hline Često je neugodno raditi s osobljem s drugih bolničkih odjela. & 2,70 & 1,109 \\
\hline Promjene smjena su za bolničke bolesnike problematične. & 2,69 & 1,026 \\
\hline Osoblje se boji postavljati pitanja kad im se čini da nešto nije u redu. & 2,66 & 1,281 \\
\hline $\begin{array}{l}\text { U slučaju povećane količine posla moj supervizor/rukovoditelj traži od nas da radimo brže, čak i pod cijenu rada na } \\
\text { prečac. }\end{array}$ & 2,62 & 1,266 \\
\hline Imamo dovoljno osoblja za obavljanje radnih zadaća. & 2,56 & 1,078 \\
\hline Aktivnosti bolničkog menadžmenta pokazuju da je sigurnost bolesnika vrhunski problem. & 2,48 & 1,024 \\
\hline Koristimo više osoblja za povremenu ispomoć nego što je potrebno za pružanje najbolje njege. & 2,41 & 1,044 \\
\hline Na ovom odjelu imamo problema sa sigurnošću bolesnika. & 2,34 & 1,103 \\
\hline Moj supervizor/rukovoditelj zanemaruje probleme sigurnosti bolesnika koji se opetovano ponavljaju. & 2,30 & 1,251 \\
\hline Ocijenite prosječnu razinu sigurnosti bolesnika na svom radnom mjestu/odjelu. & 2,28 & 0,81 \\
\hline
\end{tabular}

Izvor: Vincek, V. Sigurnost bolesnika u zdravstvenom sustavu - diplomski rad, Varaždin: Sveučilište Sjever, 2020.

Hi-kvadrat testom dobiveni su rezultati koji pokazuju da godine radnog staža ne utječu na ocjenu sigurnosti bolesnika $(p=, 05)$. Time je potvrđena prva hipoteza. Iz opaženih vrijednosti vidi se da sudionici s nižom razinom obrazovanja češće daju ocjene odličan i vrlo dobar. Uz testiranu razinu signifikantnosti od 5\%, može se odbaciti treća hipoteza i prihvatiti da postoji povezanost između testiranih varijabli, odnosno da se s povećanjem stupnja obrazovanja smanjuje ocjena sigurnosti bolesnika $(p<0,05)$.

\section{Rasprava}

Rezultati istraživanja prikazani su u tablici 2 i ukazuju na to da sudionici u istraživanju percipiraju kako mogu iznositi svoje mišljenje o mogućim negativnim učincima liječenja (srednju vrijednost 3,70). Isto tako, istraživanje je pokazalo da se osoblje međusobno organizira kako bi obavilo posao (srednja vrijednost odgovora 3,81), ali da pritom ne umanjuje sigurnost bolesnika (srednja vrijednost 3,53). Ako se vrši komparacija s drugim istraživanjima, poput Šklebarova istraživanja (2015) u kojem je korištena ista metoda kao u ovom istraživanju, rezultati pokazuju isto. Šklebar je u svo- jem istraživanju identificirao da 82 \% sudionika može slobodno upozoravati ako identificira nešto što može ugroziti sigurnost bolesnika. $U$ istom istraživanju uočeno je da se 82 \% sudionika slaže s tvrdnjom da se međusobno organiziraju kada je potrebno odraditi velik broj aktivnosti [15]. Istraživanje autorice Sochalski (2004) pokazuje da je procjena kvalitete zdravstvene njege povezana s radnim opterećenjem medicinskih sestara [16].

Jedna od presudnih varijabli koja može utjecati na sigurnost bolesnika je komunikacija i dostupnost informacijskog sustava u kojem se nalaze svi podaci o bolesnicima. Neadekvatna komunikacija između zaposlenika, odnosno medicinskog tima, također može biti jedan od razloga zbog kojeg sigurnost bolesnika opada. Potrebno je istaknuti da, ako se sigurnost promatra kroz aspekt kvalitetnog upravljanja organizacijom, norma ISO EN 15224:2017 ističe da dokumentacija i dokumentirane informacije $u$ organizaciji moraju biti dostupne sukladno potrebi, odnosno zaposlenici moraju imati mogućnost uvida u sve relevantne informacije za pružanje kvalitetne usluge bolesnicima [17]. Te informacije mogu uključivati definirane radne upute, odnosno informacije o samom bolesniku te medicinskim i drugim 
postupcima koji su provedeni nad njim. Nadalje, neophodno je osigurati i razvijati politiku kvalitete koja je usmjerena prema bolesniku te koja bolesnika i njegove potrebe stavlja na prvo mjesto. No, za osiguranje takve politike kvalitete nužno je osigurati adekvatno obrazovanje osoblja što je također zahtjev norme ISO EN 15224:2017 s obzirom na to da samo obrazovani zaposlenici koji imaju svijest o važnosti sigurnosti pacijenta mogu doprinijeti povećanju iste [17].

Istraživanjem je utvrđeno da je komunikacija između osoblja često nedostatna što je vidljivo u činjenici da se medicinske sestre / medicinski tehničari boje postaviti pitanja kada im se čini da nešto nije u redu (srednja vrijednost 2,66 ). Nadalje, sudionici istraživanja percipiraju da rukovodeće osoblje zanemaruje probleme sigurnosti koji se pojavljuju (srednja vrijednost odgovora od 2,30). Ako se rezultati usporede s rezultatima istraživanja autora Šklebara, utvrđeno je da se s ovom tvrdnjom slaže $81 \%$ ispitanika, što vrijedi i za strah medicinskih sestara da postave pitanje kad uoče da nešto nije u redu. Isto tako, utvrđeno je postojanje problema prilikom zamjene smjena jer sudionici smatraju da se izgube važni podaci o sigurnosti bolesnika (aritmetička sredina 2,71$)$ što je ponovno potvrđeno u Šklebarovu istraživanju u kojem se 71 \% sudionika slaže s tom tvrdnjom [15]. Drugim riječima, prilikom predaje smjene može doći do nedovoljno dobre komunikacije što može ugroziti sigurnost bolesnika. Autori navode da su za adekvatnu skrb kod rukovodećeg osoblja potrebne vještine upravljanja jer one izravno utječu na ishode skrbi [18, 19].

Kad se govori o preventivnim mjerama, rezultati pokazuju da medicinske sestre aktivno poduzimaju mjere koje su usmjerene prema povećanju sigurnosti bolesnika što je vidljivo u odgovoru "Mi aktivno poduzimamo mjere za poboljšanje sigurnosti bolesnika" uz srednju vrijednost odgovara 3,81. To ujedno ukazuje i na razvijenu svijest medicinskih sestara vezano za sigurnost pacijenata što može smanjiti rizik od pojave neželjenog događaja. Medicinske sestre mogu biti jedna od komponenti koja može utjecati na sigurnost pacijenta s obzirom na to da mogu prepoznati ugroze koje mogu narušiti sigurnost pacijenata i predložiti preventivne mjere. Navedeno je u skladu sa zahtjevom norme sustava upravljanja kvalitetom ISO 15224:2016. Dobivene rezultate potvrđuju rezultati Šklebarovua istraživanja u kojem je utvrđeno da 89 \% sudionika poduzima mjere usmjerene prema povećanju sigurnosti bolesnika [20]. Kad se govori o opterećenosti osoblja, s obzirom na opterećenost medicinskih sestara, uočeno je da sudionici percipiraju kako postoji deficit osoblja zbog čega može doći i do smanjenja sigurnosti pacijenata [21] te sudionici smatraju da sigurnost pacijenta nije najveći prioritet rukovodećeg osoblja (aritmetička sredina 2,48) [20].

Istraživanje pokazuje da nedostatak osoblja i nedovoljno razvijena komunikacija prilikom predaje smjene može ugroziti sigurnost bolesnika. Isto tako, u istraživanju je utvrđeno postojanje razlike u percepciji sigurnosti bolesnika kod medicinskih sestara. Zaposlenici koji imaju manje staža percipiraju sigurnost kao bolju u odnosu na zaposlenike $s$ većim radnim iskustvom. S obzirom na razinu obrazovanja, ispitanici jednako percipiraju sigurnost pacijenata.

\section{Zaključak}

Uzevši u obzir sve veće zahtjeve i izazove s kojima se susreće zdravstveni sustav, odnosno bolničke organizacije, sigurnost bolesnika postaje imperativ. Osim što je sigurnost bolesnika jedan od pokazatelja kvalitete pružene zdravstvene usluge i definirana je zakonskim propisima, sigurnost bolesnika može se sagledavati i putem prizme kvalitetnog upravljanja organizacijom, odnosno sustava upravljanja kvalitetom. Uz činjenicu da postoji niz neželjenih događaja koji će rezultirati smanjenjem sigurnosti bolesnika, proizlazi zaključak da se putem sustava upravljanja kvalitetom i pomoću načela kvalitetnog upravljanja koje ističe norma ISO EN 15224:2017 može povećati sigurnost bolesnika, točnije, može se smanjiti rizik od mogućih neželjenih događaja.

Za povećanje sigurnosti bolesnika u zdravstvenom sustavu preporučuje se provođenje analize rizika nekom od metoda poput FMEA (Failure mode and effects analysis), a na temelju koje se mogu identificirati mjesta u procesu na kojima postoji mogućnost pojave neželjenog događaja i ugroze koja bi mogla narušiti sigurnost pacijenta [22].

Stalno poboljšanje i dizajniranje zdravstvenog procesa također može biti osnova za povećanje sigurnosti pacijenta, a mogu se upotrebljavati metode kao što je Lean 6 Sigma proizašla iz japanskog pogleda na kvalitetu koji zagovara stalna svakodnevna poboljšanja [23].

Važno je osvještavati prijavu neželjenog događaja, a poznato je da visokoobrazovane medicinske sestre češće prijavljuju neželjene događaje. Potrebno je uvoditi znanja o kritičnim, to jest, graničnim slučajevima iz područja zdravstvene njege te metodama za njihovo prevladavanje, poboljšati uvjete rada u zdravstvenim ustanovama, aktivno uključivati bolesnika i njegovu obitelj u daljnji razvoj smjernica te odluka o sigurnosti pacijenata kako bi kultura zdravstvenih ustanova prerasla iz „kulture srama u kulturu sigurnosti" [20].

Optimalna sigurnost bolesnika može se omogućiti osiguranjem kompetentnosti medicinskih sestara, što je na tragu mogućnosti sagledavanja šire perspektive i veće svijesti o važnosti sigurnosti pacijenata. Kompetentnost i razumijevanje važnosti sigurnosti bolesnika kod rukovodećih osoba na bolničkom odjelu te općenito u zdravstvenom sustavu može biti osnova za povećanje i promicanje sigurnosti bolesnika te razvoja mjera i postupaka koji će biti usmjereni prema njezinu povećanju.

\section{Nema sukoba interesa}

\section{Authors declare no conflict of interest}




\section{Literatura/References}

[1] Emanuel L, Berwick, D, Conway, J, Combes, J, Hatlie, M, Leape, L, Reason, J, Schyve P, 2009. What Exactly Is Patient Safety? Journal of Medical Regulation. 2009: 13-24.

[2] Europska komisija, 2014. Priopćenje za tisak. Sigurnost pacijenata: postignuti napredak nije dovoljan. Bruxelles: Europska komisija.

[3] WHO, »Data and statistics, « 2020. [Internet]. Pristupljeno 17. 5. 2021. https://www.euro.who.int/en/health-topics/Health-systems/patientsafety/data-and-statistics.

[4] Xuanyue, M, Yanli, N, Hao, C, Pengli, J i Mingming, Z, 2013. Literature review regarding patient safety culture. Journal of Evidence-Based Medicine, 6; 1: 43-9.

[5] Kirk, S, Parker, D, Claridge, T, Esmail, A i Marshall, M, 2007. Patient safety culture in primary care: developing a theoretical framework for practical use. BMJ Quality \& Safety, 16; 4: 313-20.

[6] Mitchell, I, Schuster, A, Smith, K, Pronovost, P Wu, A, 2016. Patient safety incident reporting: a qualitative study of thoughts and perceptions of experts 15 years after 'To Err is Human'. BMJ quality \& safety, 25; 2: 92-9.

[7] Carey, K, Stefos, T, 2011. Measuring the cost of hospital adverse patient safety events. Health economics, 20; 12: 1417-30.

[8] Republika Hrvatska, Zakon o zdravstvenoj zaštiti NN 100/18, 125/19, 2019.

[9] Lončarić, I, Stavljenić Rukavina, I, 2017. Sigurnost bolesnika kao standard kvalitete u zdravstvu. Zbornik sveučilišta Libertas, 357-66.

[10] Streimelweger, B, Wac, K, Seiringer, W., 2020. Human-Factor-Based Risk Management in the Healthcare to Improve Patient Safety. In Start-Ups and SMEs: Concepts, Methodologies, Tools, and Applications (453-468). IGI Global.

[11] Republika Hrvatska, Zakon o kvaliteti zdravstvene zaštite NN 118/2018, 2018.

[12] Republika Hrvatska, Pravilnik o standardima kvalitete zdravstvene zaštite i načinu njihove primjene NN 79/2011, 2011.
[13] Jang, HE, Song, Y, Kang, HY, 2017. Nurses' perception of patient safety culture and safety control in patient safety management activities. Journal of Korean Academy of Nursing Administration, 23; 4: 45059.

[14] Vincek, V, 2020. Sigurnost bolesnika u zdravstvenom sustavu. (Diplomski rad). Varaždin: Sveučilište Sjever.

[15] Šklebar, I, 2015. Osobitosti kulture bolesnikove sigurnosti u Općoj bolnici Bjelovar i bolnicama sličnih karakteristika. Radovi Zavoda za znanstvenoistraživački i umjetnički rad u Bjelovaru, 9: 47-67.

[16] Sochalski, J, 2004. Is More Better? The Relationship between Nurse Staffing and the Quality of Nursing Care in Hospitals. Medical Care, 1167-73.

[17] ISO EN 15224, Usluge u zdravstvu - Sustavi upravljanja kvalitetom Zahtjevi utemeljeni na ISO 9001:2015, International organization for standardization, 2017.

[18] Kim, K, Moon S Y, Eun JS, 2018. Exploring the influence of nursing work environment and patient safety culture on missed nursing care in Korea. Asian nursing research, 2018: 121-26.

[19] Mardon, RE, Khanna, K, Sorra J, Dyer, N, Famolaro T, 2010. Exploring relationships between hospital patient safety culture and adverse events. Journal of Patient Safety, 6; 4: 226-32.

[20] Neuberg, M, Meštrović, T, Kozina, G, 2020. Patient safety measures and safety culture indicators in health care arena. U: Modern Societys Diverse Challenges. Celec, Robert (ur.). Hamburg: Verlag Dr. Kovač, 2020. str. 57-75 doi:http://d-nb.info/1201574293

[21] Hodak, J, 2016. Mišljenja medicinskih sestara/tehničara o neželjenim događajima tijekom procesa sestrinske skrbi u KBC Osijek. Diplomski rad. Osijek: Medicinski fakultet Sveučilišta u Osijeku.

[22] Van, KA, Nogueira, L, Gustafson, D, Tieu, W, Averch, TD, Kim, FJ, 2017 The Culture of Patient Safety. Practice: Systematic Review. Urology practice, 2017: 296-301.

[23] Latino, RJ, Flood, A, 2004. Optimizing FMEA and RCA efforts in health care. Journal of Healthcare Risk Management, 2004: 21-8. 